Published in "Langmuir 23(19): 9618-9628, 2007"

which should be cited to refer to this work.

\title{
Structural and Rheological Investigation of Fd3m Inverse Micellar Cubic Phases
}

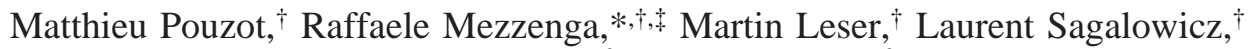 \\ Samuel Guillot, ${ }^{\S}$ and Otto Glatter ${ }^{\S}$ \\ Nestlé Research Center, Nestec Ltd., Vers-chez-les-Blanc, CH-1000 Lausanne 26, Switzerland, Department \\ of Physics, University of Fribourg, Perolles, Fribourg CH-1700, Switzerland, and Institute of Chemistry, \\ University of Graz, Graz, Austria
}

\begin{abstract}
In the present study we demonstrate that a bulk inverse micellar cubic phase of $F d 3 m$ structure can be obtained by adding a hydrophobic component, such as the food-grade limonene, to the binary system monolinolein/water in a well-defined composition. The $F d 3 m$ structure studied in this work had a very slow kinetics of formation, as a consequence of partitioning of water into two types of micelle populations with different sizes. The $F d 3 m$ structure formed at a ratio of limonene oil to total lipids of $\alpha=0.4$ is stable in the bulk up to a maximum hydration of 12.68 wt $\%$ water, beyond which it starts to coexist with dispersed water. At full hydration, by combining small-angle X-ray scattering and available topological models, the inverse micellar cubic phase of $F d 3 m$ structure was shown to be formed by 16 small micelles and 8 larger micelles per cubic lattice cell $\left(\mathrm{Q}^{227}\right.$ group), with radii of the micellar polar cores ranging between 1 and $3 \mathrm{~nm}$ and 149-168 monolinolein molecules per micelle depending on the water content. The temperature dependence of the structural and rheological properties of the $F d 3 m$ mesophase was investigated using SAXS, rheology, and turbidimetry. It appeared that the $F d 3 m$ phase underwent crystallization below $18^{\circ} \mathrm{C}$ and began melting in an inverse microemulsion ( $\mathrm{L}_{2}$ phase) coexisting with water above $28.5^{\circ} \mathrm{C}$ with complete melting obtained at $40-45^{\circ} \mathrm{C}$, as evidenced by SAXS and rheology. Macroscopic phase separation between the $\mathrm{L}_{2}$ phase and excess water was observed with time at higher temperatures. The investigation of the viscoelastic properties of the $F d 3 m$ inverse discrete micellar cubic phase revealed a rheological signature similar to that of the bicontinuous cubic phases $P n 3 m$ and $I a 3 d$ observed in homologous binary systems. However, the $F d 3 m$ phase presented a complex set of slower relaxation mechanisms leading to a shift by 1 order of magnitude of the dominant relaxation times and whole relaxation spectrum, as compared to those of inverse bicontinuous cubic phases. These findings have been tentatively explained by (i) the multiple relaxation of micelles upon deformation, (ii) the small hydration level of the $F d 3 m$ phase, and (iii) the low temperature at which this phase can be observed.
\end{abstract}

\section{Introduction}

Self-assembly of surfactants and food emulsifiers in the presence of water is known to give rise to complex liquid crystalline (LC) structures. ${ }^{1-4}$ These lyotropic mesophases undergo phase transitions upon changes in the temperature and concentration.

Geometrical features of these structures have been extensively described by topological considerations such as those based on the critical packing parameter (cpp), ${ }^{5,6}$ mean and Gaussian curvatures $(\langle H\rangle, \kappa),{ }^{7,8}$ infinite periodic minimal surfaces (IPMS), ${ }^{9}$

* To whom correspondence should be addressed. Phone: + 4126300 9066. Fax: + 41263009747 .E-mail: raffaele.mezzenga@rdls.nestle.com; raffaele.mezzenga@unifr.ch.

$\dagger$ Nestec Ltd.

$\doteqdot$ University of Fribourg.

$\S$ University of Graz.

(1) Krog, N. J. Food Emulsifiers and their chemical and physical properties. In Food Emulsions; Friberg, S. E., Larsson, K., Eds.; Marcel Dekker Inc.: New York, 1997; p 141.

(2) Hyde, S. T.; Anderson, B.; Ericsson, O.; Larsson, K. Z. Kristallogr. 1984, $168,213$.

(3) Barfold, N. M.; Krog, N. J.; Buccheim, W. In Food Proteins. Part Structural and Functional Relationships; Kinsella, J. E., Ed.; American Oil Chemists Society: Champaign, IL, 1989; p 144.

(4) Lutton, E. S.; Stauffer, C. E.; Martin, J. B.; Fehl, A. S. J. Colloid Interface Sci. 1969, 30, 283.

(5) Israelachvili, J. N.; Mitchell, D. J;. Ninham, B. W. J. Chem. Soc., Faraday Trans. 1976, 11, 1525 .

(6) Tanford, C. The hydrophobic effects: formation of micelles and biological membranes; Wiley: New York, 1980.

(7) Lindblom, G.; Rilfors, L. Biochim. Biophys. Acta 1989, 988, 221.

(8) Seddon, J. M. Biochim. Biophys. Acta 1990, 1031, 1.

(9) Scriven, L. E. Nature 1976, 263, 123. and minimization of packing frustration constraints. ${ }^{10}$ More recently, physically inspired approaches based on minimization of the total free energy have been proposed to predict and describe self-assembled morphologies in these systems. ${ }^{11-13}$ Solving the minimization of the total free energy by self-consistent field theory (SCFT) has proved to be a powerful method to predict equilibrium structures. ${ }^{11,12}$

In general, by increasing the mean negative curvature of the lipid-water interface, by means of the water concentration or temperature, inverse liquid crystalline phases different than lamellar can be obtained, such as inverse bicontinuous cubic phases $\left(\mathrm{V}_{2}\right)$, inverse hexagonal phases $\left(\mathrm{H}_{2}\right)$, or inverse microemulsions $\left(\mathrm{L}_{2}\right)$.

Liquid crystalline phases of this type have been actively studied due to their relevance for cell membrane functionalities ${ }^{8,14-16}$ such as fusion phenomena ${ }^{17,18}$ and integrity, or even in vivo

(10) Duesing, P. M.; Templer, R. H.; Seddon, J. M. Langmuir 1997, 13, 351.

(11) Matsen, M. W.; Schick M. Phys. Rev. Lett. 1994, 72, 2660.

(12) Mezzenga, R.; Bo Lee, W.; Frederickson, G. H. Trends Food Sci. Technol. 2006, 17, 220 .

(13) Mezzenga, R.; Schurtenberger, P.; Burbidge, A.; Michel, M. Nat. Mater. $\mathbf{2 0 0 5}, 4,729$.

(14) Seddon, J. M.; Bartle, E. A.; Mingins, J. J. Phys.: Condens. Matter 1990, 2,285

(15) Luzzati, V.; Vargas, R.; Mariani, P.; Gulik, A.; Delacroix, H. J. Mol. Biol. 1993, 229, 540 .

(16) Mariani, P.; Luzzati, V.; Delacroix, H. J. Mol. Biol. 1988, 204, 165

(17) Nieva, J. L.; Alonso, A.; Basanez, G.; Goni, F. M.; Gulik, A.; Vargas, R.; Luzzati, V. FEBS Lett. 1995, 368, 143.

(18) Siegel, D. J.; Banschbach, A.; Alford, H.; Ellens, L. J.; Lis, P. J.; Quinn, P. L.; Yeagel; Bentz, J. Biochemistry 1989, 28, 3703. 
digestion of lipidic food emulsions with release of degraded subproducts. ${ }^{19-22}$

In parallel to the study of lipid-based lyotropic LC phases in the bulk, their technological relevance for food, cosmetics, and pharmaceutics applications has motivated the study of dispersed particles with internal LC structures ${ }^{23-28}$ analogous to those characteristic of the bulk state. These particles have been proposed as vehicles for the controlled delivery of drugs and bioactive ingredients ${ }^{29}$ or as reactors for increasing the yield of flavoring compound synthesis. ${ }^{30-32}$

One of the most extensively investigated classes of lipidbased LC systems is that based on monoglycerides and water. Among monoglycerides, phase diagrams obtained by selfassembly of water with fully aliphatic chains, ${ }^{1}$ monooleins with one unsaturation, ${ }^{33}$ or monolinolein with two unsaturations ${ }^{26}$ have been described by small-angle X-ray scattering (SAXS). In the latter case, detailed rheology characterization has also been reported. ${ }^{34}$

The corresponding phase diagram was shown to be structurally rich with the presence of a plastic lamellar phase $\left(\mathrm{L}_{\alpha}\right)$ for the low water contents and temperatures, characterized by $\langle H\rangle=0$. With increasing hydration of the system, isotropic inverse bicontinuous cubic phases of the $I a 3 d$ and $P n 3 m$ types were formed, characterized by an increase in the negative value of the curvature. Both types of cubic phases transformed into anisotropic inverse hexagonal mesophase $\mathrm{H}_{2}$ beyond $60^{\circ} \mathrm{C}$. Finally an inverse microemulsion, $\mathrm{L}_{2}$, was observed at higher temperature above $80^{\circ} \mathrm{C}$.

The same monolinolein/water system, upon oil addition (i.e., ternary mixture of monolinolein/tetradecane oil/water), was shown to exhibit an additional LC phase, not present in the monolinolein/water binary mixture: an inverse discrete micellar cubic phase of the $F d 3 m$ type ( $\mathrm{Q}^{227}$ group), as revealed by SAXS measurement. ${ }^{28}$

The structure of the $F d 3 m$ micellar cubic phase comprised two types of micelles with different sizes organized in a double diamond network. In this network, the largest eight micelles are of $3 m$ symmetry and the smallest sixteen micelles of $43 m$ symmetry. ${ }^{35-41,67}$ These micelles are not spherical but have a dodecahedron and a hexakaidecahedron shape, respectively,

(19) Lindstrom, M.; Ljusberg-Wahren, H.; Larsson, K.; Borgstrom, B. Lipids 1981, 16, 749 .

(20) Borné, J.; Nylander, T.; Khan, A. Langmuir 2002, 18, 8972

(21) Kossena, G. A.; Charman, W. N.; Boyd, B. J.; Dunstan, D. E.; Porter,

C. J. H. J. Pharm. Sci. 2004.

(22) Kossena, G. A.; Charman, W. N.; Boyd, B. J.; Porter, C. J. H. J. Pharm. Sci. 2005, 94, 481.

(23) Leser, M. E.; Sagalowicz, L.; Michel, M.; Watzke, H. J Adv. Colloid Interface Sci. 2006, 123, 125.

(24) Sagalowicz, L.; Leser, M. E.; Watzke, H. J.; Michel, M. Trends Food Sci. Technol. 2006, 17, 204.

(25) Spicer, P. T.; Hayden, K. L.; Lynch, M. L.; Ofori-Boateng, A.; Burns, J. L. Langmuir 2001, 17, 5748 .

(26) de Campo, L.; Yaghmur, A.; Sagalowicz, L.; Leser, M. E.; Watzke, H. J.; Glatter, O. Langmuir 2004, 20, 5254.

(27) Gustafsson, J.; Ljusberg-Wahren, H.; Almgren, M.; Larsson, K. Langmuir 1996, 12,4611

(28) Yaghmur, A.; de Campo, L.; Salentinig, S.; Sagalowicz, L.; Leser, M.

E.; Glatter, O. Langmuir 2006, 22, 517.

(29) Boyd, B. J. Int. J. Pharm. 2003, 260, 239.

(30) Vauthey, S.; Visani, P.; Frossard, P.; Garti, N.; Leser, M. E.; Watzke, H. J J. Dispersion Sci. Technol. 2000, 21, 263.

(31) Vauthey, S.; Milo, C.; Frossard, P.; Garti, N.; Leser, M. E.; Watzke, H. J. J. Agric. Food Chem. 2000, 48, 4808.

(32) Blank, I.; Davideck, T.; Devaud, S.; Sagalowicz, L.; Leser, M. E.; Michel, M. Formation of 4-hydroxy-5-methyl-3( $2 \mathrm{H}$ )-furanone (norfuraneol) in structured fluids. In Flavour Science: Recent Advances and Trends; Bredie, P., Eds.; Elsevier: New York, 2006.

(33) Qiu, H.; Caffrey, M. Biomaterials 2000, 21, 223.

(34) Mezzenga, R.; Meyer, C.; Servais, C.; Romoscanu, A.; Sagalowicz, L.; Hayward, R. C. Langmuir 2005, 21, 3322.

(35) Seddon, J. M. Biochemistry 1990, 29, 7997.

(36) Seddon, J. M.; Neelofar, Z.; Templer, R. H.; McElhaney, R. N.; Mannock, D. A. Langmuir 1996, 12, 5250. which results from the minimization of the high packing frustration constraints on the alkyl tails associated with the $F d 3 m$ arrangement.

The $F d 3 m$ structure has been documented in various water/ amphiphile systems swollen by oil, such as block copolymers, ${ }^{42-46}$ and has already been observed in aqueous simultaneous mixtures of distinct lipids with different amphiphilicities, as in the case of phospholipid/fatty acid systems ${ }^{39,47}$ or phospholipid/fatty alcohol binary mixtures in water. ${ }^{35,37,39,47,48}$

The different nature of mixed lipids, then the diverse amphiphilicity, and finally the specific mean curvature of each lipid were invoked in early works as the main reasons leading to the formation of micelles with different sizes and thus to different negative curvatures. This argument allowed explaining the different levels of partitioning of the two lipids on the surface of the two different types of micelles. ${ }^{37}$

However, the $F d 3 m$ structure has also been observed in single lipid-composed aqueous mesophases, as in the case of glycolipid emulsifiers (e.g., diphytanylglucosylglycerol/water or dialky1xylopyranosylglycerol/water systems), which has allowed, at least in the case of a few systems, declining the above-mentioned hypothesis. ${ }^{36,49}$

There is actual consensus on the fact that formation of an $F d 3 m$ micellar phase is promoted in systems where lipids have a negative preferred curvature $\left(\left\langle H_{0}\right\rangle\right)$, which is practically realized when long alkyl hydrophobic tails are associated with weakly hydrated hydrophilic heads. ${ }^{36}$

In this respect, the documented appearance of the $F d 3 m$ micellar cubic phase upon blending monoglycerides and water with oil might be linked to an increased hydrophobic nature of the complex fluid. In this fluid, the added oil swells the hydrophobic domains associated with alkyl tails ${ }^{28,42,45}$ (i.e., an increase in the cpp value), partially releases their frustration, and decreases the hydration level of hydrophilic heads. ${ }^{35,48}$ This then promotes the reorganization of the mesophases into an $F d 3 m$ inverse structure with more negative curvature.

Furthermore, possible use of inverse $F d 3 m$ micellar cubic phases has been hypothesized for in vivo protection of cell membrane integrity under lipolysis. ${ }^{15,36,38}$ Indeed, this is because lipolysis of the phospholipid-based membrane upon external aggression may give rise to a mixture of fatty acids and phospholipids known to self-assemble into $F d 3 m$ LC phases. Since $F d 3 m$ micellar cubic phases are discrete and isolated from the external environment, contrary to bicontinuous cubic phases, ${ }^{40,41}$ their use as membrane templates can possibly prevent uncontrolled leakage of the whole biological cell.

Very few studies have been reported for the rheological behavior of LC phases. ${ }^{46,50-60}$ The mechanical relaxation of these

(37) Seddon, J. M.; Robins, J.; Gulik-Krzywicki, T.; Delacroix, H. Phys. Chem. Chem. Phys. 2000, 2, 4485.

(38) Delacroix, H.; Gulik-Krzywicki, T.; Seddon, J. M. J. Mol. Biol. 1996, 258,88 .

(39) Luzzati, V.; Vargas, R.; Gulik, A.; Mariani, P.; Seddon, J. M.; Rivas, E. Biochemistry 1992, 31, 279.

(40) Hendrikx, Y.; Sotta, P.; Seddon, J. M.; Dutheillet, Y.; Bartle, E. A. Liq. Cryst. 1994, 16, 893 .

(41) Orädd, G.; Lindblom, G.; Fontell, K.; Ljusberg-Wahren, H. Biophys. J. 1995, 68, 1856.

(42) Uddin, M. H.; Rodriguez, C.; Watanabe, K.; Lopez-Quintela, A.; Kato, T.; Furukawa, H.; Harashima, A.; Kunieda, H. Langmuir 2001, 17, 5169. (43) Alexandridis, P.; Olsson, U.; Lindman, B. Langmuir 1996, 12, 1419. (44) Alexandridis, P.; Olsson, U.; Lindman, B. Langmuir 1997, 13, 23.

(45) Alexandridis, P.; Olsson, U.; Lindman, B. Langmuir 1998, 14, 2627.

(46) Rodriguez-Abreu, C.; Acharaya, D.; Aramaki, K.; Kunieda, H. Colloids Surf., A: Physiochem. Eng. Aspects 2005, 269, 59.

(47) Koynova, R.; Tenchov, B.; Rapp, G. Chem. Phys. Lipids 1997, 88, 45 (48) Huang, Z.; Seddon, J. M; Templer, R. H. Chem. Phys. Lipids 1996, 82,

(49) Minamikawa, H.; Hato, M. Langmuir 1998, 14, 4503. 
phases has been tentatively explained by the "slip planes" model. ${ }^{46,58,60}$ However, this model is based on a nonlinear response of the system to mechanical stress and therefore does not apply to the low strain/stress conditions of the linear viscoelastic regime.

To our knowledge, the only rheological study in the linear viscoelastic regime for inverse discrete micellar cubic phases of the $F d 3 m$ type is the one reported by Rodriguez-Abreu et al. ${ }^{46}$ for an aqueous PEO-PPO-PEO block copolymer in aqueous solution swollen by addition of xylene oil. Their study shows that the $F d 3 m$ mesophase behaves like a hard gel-like material with a well-defined yield stress. The frequency dependence of both storage and loss moduli was also presented, without, however, providing a detailed rationale of the longest relaxation time as a function of the temperature or composition.

The longest relaxation time evolution when moving throughout the phase diagram or full relaxation spectrum can, in principle, be extracted from the storage and loss modulus frequency dependence, by using a generalized Maxwell model formalism, or specific Laplace inversion algorithms, as was previously done for monolinolein/water binary systems. ${ }^{34}$ The longest relaxation time provides single-parameter information on the viscoelastic behavior of the lipid-water interface. While this time can be used to distinguish among different phases, the relaxation spectrum allows capturing other relaxations occurring in the complex LC phases, such as those associated with the mobility of hydrophilic and hydrophobic domains. ${ }^{13}$

Finally, rheology can be used as a complementary tool to SAXS to probe thermally or lyotropically induced phase transitions. ${ }^{13,34,50,57,61}$

In the present study, we combined SAXS and rheology to investigate the structure and viscoelastic properties of an inverse discrete micellar cubic phase of the $F d 3 m$ type, obtained in the bulk from the monolinolein/limonene oil/water ternary system. A similar system was already studied but in the emulsified state, for which a rheological characterization was not possible. ${ }^{66}$ Topological parameters such as the size of the micelles and the number of lipid molecules per micelle have been calculated from SAXS data. The composition was determined by using structural models previously developed for inverse cubic micellar phases. ${ }^{42,49}$ The thermal behavior of the $F d 3 m$ phase and the associated evolution of the structural parameters of that mesophase are also addressed in this paper.

\section{Materials and Methods}

Materials and Sample Preparation. Dimodan U was a generous gift (from Danisco Brabrand, Denmark) and was used as received. This commercial-grade form of monolinolein contains more than 98 wt $\%$ monoglyceride. The hydrocarbon tail consists predominantly of C18 chains (91\%), distributed as follows: C18:2 (61.9\%), C18:1

(50) Feng, S. H.; Wang, H. X.; Zhang, G. Y.; Xie, X. L. Prog. Chem. 2004, $16,687$.

(51) Franco, J. M.; Munoz, J.; Gallegos, C. Langmuir 1995, 11, 669

(52) Kelarakis, A.; Castelleto, V.; Chaibundit, C.; Fundin, J.; Havredaki, V.; Hamley, I. W.; Booth, C. Langmuir 2001, 17, 4232.

(53) Messé, L.; Corvasié, L.; Young, R. N.; Ryan, A. J. Langmuir 2002, 18 , 2564.

(54) Montalvo, G.; Valiente, M.; Rodenas, E. Langmuir 1996, 12, 5202.

(55) Moros, J. E.; Cordobés, F.; Gallegos, C.; Franco, J. M. J. Dispersion Sci. Technol. 2001, 22, 405.

(56) Pitzalis, P.; Monduzzi, M.; Krog, N. J.; Larsson, H.; Ljusberg-Wahren, H.; Nylander, T. Langmuir 2000, 16, 6358.

(57) Wang, H. X.; Zhang, G. Y.; Feng, S. H.; Xie, X. L. Colloids Surf., A: Physiochem. Eng. Aspects $\mathbf{2 0 0 5 .}$

(58) Jones, J. L.; McLeish, T. Langmuir 1995, 11, 785.

(59) Jones, J. L.; McLeish, T. Langmuir 1999, 15, 7495.

(60) Rodriguez-Abreu, C.; Garcia-Roman, M.; Kunieda, H. Langmuir 2004, 20,5235 .

(61) Sagalowicz, L.; Mezzenga, R.; Leser, M. E. Curr. Opin. Colloid Interface Sci. 2006, 11, 224.

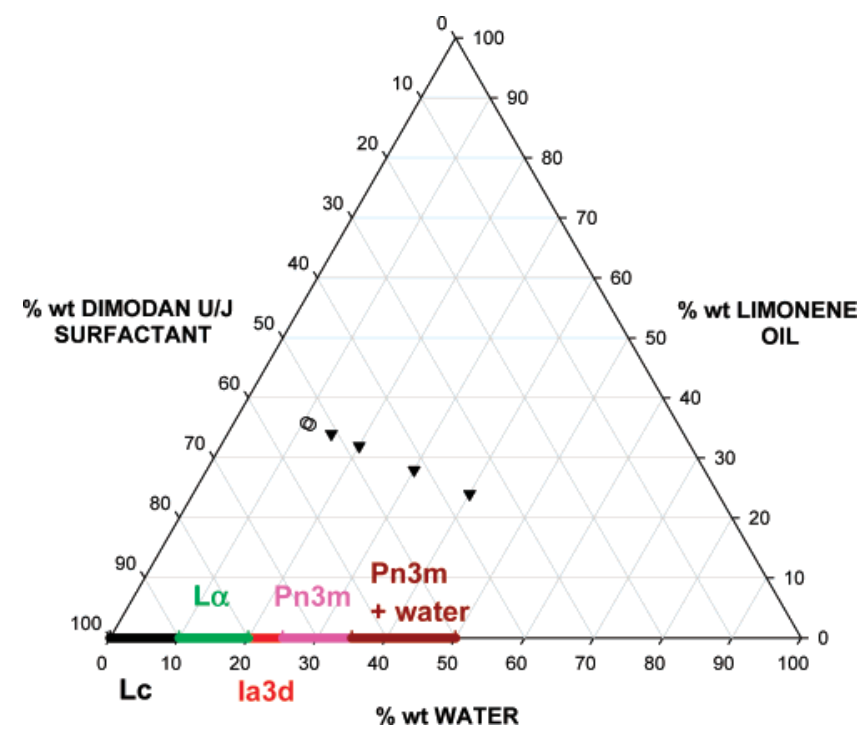

Figure 1. Composition diagram for lipid/water/limonene mixtures studied for constant $\alpha=0.4$ at $23^{\circ} \mathrm{C}$. Open circles represent samples with water contents below the full hydration of the $F d 3 m$ LC phase (i.e., below $12.68 \mathrm{wt} \%$ ). Filled triangles represent samples with water contents above the full hydration level; this corresponds to $F d 3 m$ domains coexisting with excess water domains. The binary phase diagram for $\alpha=0$ is taken from ref 34 .

(24.9\%), and C18:0 (4.2\%). Additional lipids are C16:0 chains (7.4\%) and a residual amount of diglycerides $(1.6 \%) .(R)-(+)$-Limonene oil ( $98 \%$ purum grade) was purchased from Fluka Chemika (Switzerland).

The same single batches of Dimodan $U$ and limonene oil were used for all the physical characterizations.

Samples were prepared at constant weight ratio between limonene and lipid. This was expressed by $\alpha$ defined as

$$
\alpha=\frac{\text { mass }_{\text {lim }}}{\text { mass }_{\text {lim }}+\text { mass }_{\text {mono }}}
$$

$\alpha$ was maintained at a fixed value of 0.4 in all experiments. Demineralized water was then added to the monolinolein/limonene oil mixture at different volume fractions as shown in the composition diagram represented in Figure 1. The mixture was placed in vials with sealed caps. Mixing was achieved by means of cyclic heating (up to $100{ }^{\circ} \mathrm{C}$ for a few seconds) and simultaneous shaking using a vortex. Once homogeneous mixing was achieved, the vials were cooled to room temperature, opened to insert the samples into the SAXS capillaries, and then sealed.

The capillaries of turbid aspect just after preparation were then allowed to equilibrate at a constant temperature of $23^{\circ} \mathrm{C}$ for 5 days. This allows the progressive formation of a complete transparent gel-like $F d 3 m$ phase.

For the rheological measurements, the homogeneous mixtures of the required composition were heated to the formation of the isotropic fluid and then poured into the Couette setup of the rheometer. The temperature was directly cooled to $23{ }^{\circ} \mathrm{C}$ to allow progressive formation of the $\mathrm{Fd} 3 \mathrm{~m}$ phase. Measurements were acquired at time intervals analogous to those selected for SAXS measurements.

Density Measurements. The density of the $(R)-(+)$-limonene oil and its dependence on temperature was measured using a DMA 4500 density meter (Anton Paar) with an accuracy of $\pm 1.10^{-5} \mathrm{~g} \cdot \mathrm{cm}^{-3}$. The dependence observed was fitted by the following law:

$$
\rho_{\text {lim }}=0.85682-\left(7.71222 \times 10^{-4}\right) T-\left(2.11264 \times 10^{-7}\right) T^{2}
$$

where $\rho$ is expressed in grams per cubic centimeter and temperature $(T)$ in degrees Celsius. 
The temperature dependence of the density of Dimodan U was reported previously. ${ }^{34}$ Reference tables were used for the temperature dependence of the density of demineralized water.

Turbidimetry. The time evolution of turbidity at a wavelength of $\lambda=500 \mathrm{~nm}$ was measured over 5 days for the ternary mixture at $11.2 \mathrm{wt} \%$ water and $\alpha=0.4$ using a spectrophotometer (HP 8453, Hewlett-Packard) with automatic time recording of the turbidity at a constant temperature of $23{ }^{\circ} \mathrm{C}$ maintained through a water bath.

The temperature dependence of the optical turbidity at $\lambda=500$ nm was evaluated in the range $17-30.2^{\circ} \mathrm{C}$ on an $F d 3 m$ mesophase formed at $\alpha=0.4$ with $11.2 \mathrm{wt} \%$ water after full equilibration of the bulk and over 5 days at $23{ }^{\circ} \mathrm{C}$. Measurements were done on a spectrophotometer (Uvikon 810P, Kontron Instruments) connected to a water bath as the heating device.

All the samples used for turbidity measurements were prepared according to the method described above in the Materials and Sample Preparation. The melted ternary mixture was poured into a UV cell (114-OS, Hellma) with a $1 \mathrm{~cm}$ optical path length and the cell subsequently hermetically sealed by a Teflon cap. Weight measurements performed on the cells excluded any evaporation during the time of the experiments.

Small-Angle X-ray Scattering. SAXS was used for a precise identification of the $F d 3 m$ phase in terms of lattice parameter determination and for its evolution with increasing hydration. For that study, we used a high-flux SAXSess camera (Anton Paar, Graz, Austria) at Graz University, connected to an X-ray generator (Philips, PW1730/10) operating at $40 \mathrm{kV}$ and $50 \mathrm{~mA}$ with a sealed-tube $\mathrm{Cu}$ anode. A Göbel mirror was used to convert the divergent polychromatic X-ray beam into a focused line-shaped beam of $\mathrm{Cu} \mathrm{K \alpha}$ radiation $(\lambda=0.154 \mathrm{~nm})$. The $2 \mathrm{D}$ scattering pattern was recorded by a PI-SCX fused fiber optic taper CCD camera from Princeton Instruments (a division of Roper Scientific Inc., Trenton, NJ) and integrated into the 1D scattering function. The CCD detector that was used features a $2084 \times 2084$ array with a $24 \mu \mathrm{m} \times 24 \mu \mathrm{m}$ pixel size (chip size $50 \mathrm{~mm} \times 50 \mathrm{~mm}$ ). The CCD is operated at $-30{ }^{\circ} \mathrm{C}$ with $10^{\circ} \mathrm{C}$ water-assisted cooling to reduce the thermally generated charge. Cosmic ray correction and background subtraction were performed on the $2 \mathrm{D}$ image before further data processing. The temperature of the capillary and the metallic sample holder was controlled by a Peltier element. Samples were equilibrated at $23{ }^{\circ} \mathrm{C}$ for $30 \mathrm{~min}$ before the measurements. Bulk samples were exposed to X-rays for $240 \mathrm{~s}$, three times for averaging.

Other SAXS experiments were performed at Fribourg University using a SAXSess instrument (Anton Paar) with a line collimation setup. The measurements were carried out in the $q$ range of $7.7 \times$ $10^{-2}$ to $28.5 \mathrm{~nm}^{-1}$. This corresponds to a total angular window range between $0.05^{\circ}$ and $41^{\circ}$, and the scattering vector is defined as $q=$ $[4 \pi \sin (\theta / 2)] / \lambda$. The system used a $\mathrm{Cu} \mathrm{K} \alpha$ radiation source in a sealed tube $(\lambda=1.542 \mathrm{~nm})$. The beam was attenuated by a semitransparent nickel foil beam stop. Highly sensitive SAXS imaging plate slides (reference Fuji supplier) at a distance of 264.5 $\mathrm{mm}$ from the sample were used to collect the signal under vacuum. The sample holder was temperature controlled in the range comprised from -16 to $+100{ }^{\circ} \mathrm{C}$. Measurements were performed using capillaries $1 \mathrm{~mm}$ in diameter, with a volume capacity of $100 \mu \mathrm{L}$, filled as described above. The samples, which just after preparation had the aspect of a turbid hard gel, became completely transparent, while the rigidity was preserved, after 5 days. The formation and evolution of the $F d 3 m$ phase at $23{ }^{\circ} \mathrm{C}$ were followed by SAXS by acquiring diffractograms at different times.

Diffraction data were acquired over $40 \mathrm{~min}$. When temperaturedependent measurements were performed, each temperature was maintained $30 \mathrm{~min}$ prior to the SAXS measurements to achieve thermodynamic equilibrium in the LC phases. All scattering signals were treated with SAXSquant software (Anton Paar).

The values of the lattice parameter $\left(a_{\text {lattice }}\right)$ for the $F d 3 m$ cubic mesophase were calculated using the most intense reflection (311) by using the following expression: ${ }^{28,36,39}$

$$
\frac{a_{\text {lattice }}}{d_{311}}=\left(3^{2}+1^{2}+1^{2}\right)^{1 / 2}
$$

where $d_{311}$ corresponds to the interlayer spacing for planes of Miller indices defined as $h=3, k=1$, and $l=1$. The interlayer spacing corresponding to $d_{311}$ is

$$
d_{311}=\frac{2 \pi}{q_{311}}
$$

where $q_{311}$ is the scattering vector at which the dominant reflection (311) is observed.

In the case of the $\mathrm{L}_{2}$ phase, the characteristic length of the inverse emulsion $\left(d_{\mathrm{L}_{2}}\right)$ was expressed as ${ }^{26,28}$

$$
d_{\mathrm{L}_{2}}=\frac{2 \pi}{q_{\text {peak } \mathrm{L}_{2}}}
$$

with $q_{\text {peak } \mathrm{L}_{2}}$ being the scattering vector at which the maximum of the unique diffraction peak of $\mathrm{L}_{2}$ is observed.

Optical Microscopy. Microscopy observations of a mesophase made at $\alpha=0.4$ with $11.2 \mathrm{wt} \%$ water after 5 days of full equilibration of the bulk at $23{ }^{\circ} \mathrm{C}$ were achieved on an Axioplan 2 (Zeiss). The effect of temperature on the structure was investigated at 23 and $30.2^{\circ} \mathrm{C}$ after thermal equilibration using a Peltier heating plate device (Linkam Plate THMS 600).

The samples were prepared according to the method described above in the Materials and Sample Preparation, introduced into capillary microslides (Camlab, England), which were sealed with glue, and then subjected to equilibration for 5 days at $23{ }^{\circ} \mathrm{C}$ before temperature-dependent observations were started.

Shear Rheology. The rheological study of the $F d 3 m$ phase was carried out using an Anton Paar Physica MCR 500 rheometer in a strain-controlled mode (direct strain oscillation, DSO). The measurement geometry used was a DIN concentric cylinder (CC 17, Couette cell), with an inner cylinder of $17 \mathrm{~mm}$. The temperature was controlled by a Peltier system applied on the outer edge of the Couette. To minimize water loss by evaporation, a solvent trap system with concentric Teflon disks and a low-viscosity sealing oil were used. This technique was already reported elsewhere ${ }^{34}$ and proved to minimize the water losses without perturbing the rheological measurements.

The frequency dependence of $G^{\prime}, G^{\prime \prime}$, and $\tan (\delta)$ in the range of frequencies $\omega=2 \times 10^{-3}$ to $628 \mathrm{rad} \cdot \mathrm{s}^{-1}$ was studied on $F d 3 m$ phases obtained at $\alpha=0.4$ and $11.2 \mathrm{wt} \%$ water after $t=0$ days, $t=5$ days, and $t=7$ days of equilibration at a constant temperature of $23{ }^{\circ} \mathrm{C}$. The linear viscoelastic regime was checked on separate measurements for each frequency of interest. A low strain of $10^{-2} \%$, in the linear regime, was used in the experiments

The spectrum of relaxation times was extracted by the inverse Laplace transformation ${ }^{62}$ of frequency scans of $G^{\prime}$ and $G^{\prime \prime}$, as described elsewhere for the binary system monolinolein (Dimodan $\mathrm{U}) /$ water. $^{34}$

The temperature dependence of $G^{\prime}$ and $G^{\prime \prime}$ of the $F d 3 m$ phase with $\alpha=0.4$ and 11.2 wt $\%$ water after 5 days of equilibration was determined in the linear regime at $\omega=1 \mathrm{rad} \cdot \mathrm{s}^{-1}$ and for a low strain of $10^{-2} \%$. A constant heating or cooling rate of $0.2{ }^{\circ} \mathrm{C} \cdot \mathrm{min}^{-1}$ in the range of $20-80{ }^{\circ} \mathrm{C}$ was used for measuring equilibrium LC structures.

\section{Results and Discussion}

Kinetics of Structuration and Aging of the $\mathrm{Fd} 3 \mathrm{~m}$ Phase. The ternary mixture with 11.2 wt $\%$ water and $\alpha=0.4$ (taken as a reference sample in the study) was first melted at $85^{\circ} \mathrm{C}$ into a viscous $\mathrm{L}_{2}$ liquid phase and allowed to evolve at $23{ }^{\circ} \mathrm{C}$ for 7 days. Immediately after mixing, the phase is turbid, but progressively evolves with time into a stiff and fully transparent

(62) Winter, H. H. J. Non-Newtonian Fluid Mech. 1997, 68, 225. 


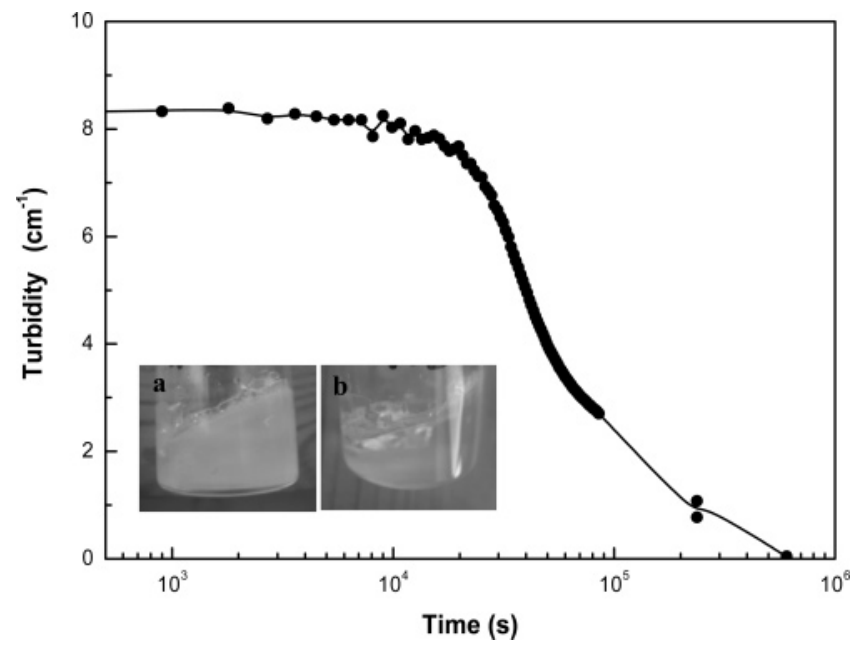

Figure 2. Time evolution of the turbidity measured at $\lambda=500 \mathrm{~nm}$ for a lipid/water/limonene mixture with $\alpha=0.4$ and 11.2 wt $\%$ water $\left(T=23{ }^{\circ} \mathrm{C}\right)$. Inset a: Picture of the sample at $23{ }^{\circ} \mathrm{C}$ just after formation. The initial high level of turbidity corresponds to the presence of phase-separated water microdomains coexisting with the $F d 3 m$ phase. Inset b: Picture of the sample at $23^{\circ} \mathrm{C}$ after 5 days. The transparency of the sample indicates that the $F d 3 m$ phase now spans alone in the mesophase.

phase, as can be seen from the turbidity curve of Figure 2. No birefringence was observed during the whole equilibration process.

SAXS measurements were carried out at $t=0$ and 5 days, and the diffractograms are identical (see Figure 3a). The scattering patterns show 11 typical reflections of the $\mathrm{Q}^{227}$ space group ( $F d 3 m$ symmetry). This indicates that the structure and the lattice parameters of the $F d 3 m$ phase are independent of time. Therefore, we attribute the turbid aspect of the sample at the beginning of the equilibration to a phase-separated morphology, in which the $F d 3 m$ phase coexists with an isotropic fluid. As will be shown later, this turbid phase corresponds to an excess of water that coexists with $\mathrm{L}_{2}$ phase micelles. Note that the coexistence of three phases in the system is in accordance with the Gibbs rule for three-component systems.

Thus, the decrease of the turbidity with time can be understood as the result of a progressive spanning of the $F d 3 m$ phase within the whole bulk by the incorporation of the free water in excess into the polar cores of the $F d 3 m$ micelles, therefore leading to the conversion into a purely transparent isotropic mesophase.

This slow structuration from a multiphase system to a full $F d 3 m$ phase may occur through a nucleation and growth mechanism. A slow kinetics has to be expected since the formation of the ordered $\mathrm{Fd} 3 \mathrm{~m}$ phase involves (i) the diffusion of water molecules through the hydrophobic shell of the micelles, (ii) the packing of water-filled micelles into a highly ordered lattice, and (iii) a change of micelle size distribution from the purely monomodal distribution present in the $\mathrm{L}_{2}$ phase to the bimodal distribution of the inverse micellar $F d 3 m$ cubic phase. This relatively slow kinetics for the $F d 3 m$ structuration was already documented for a system of hydrated phytanyl-chained glucolipid. ${ }^{49}$

As briefly discussed before, the appearance of the $F d 3 m$ phase upon the addition of limonene oil to the monolinolein/water system can possibly be related to the increase of the hydrophobic volume, initially made of the $\mathrm{C}_{18}$ alkyl tail domains, leading to a more negative value of the mean curvature. Alternatively, limonene molecules can be partitioned into the interstitial spaces of the $F d 3 m$ lattice, thus releasing the packing frustration of the
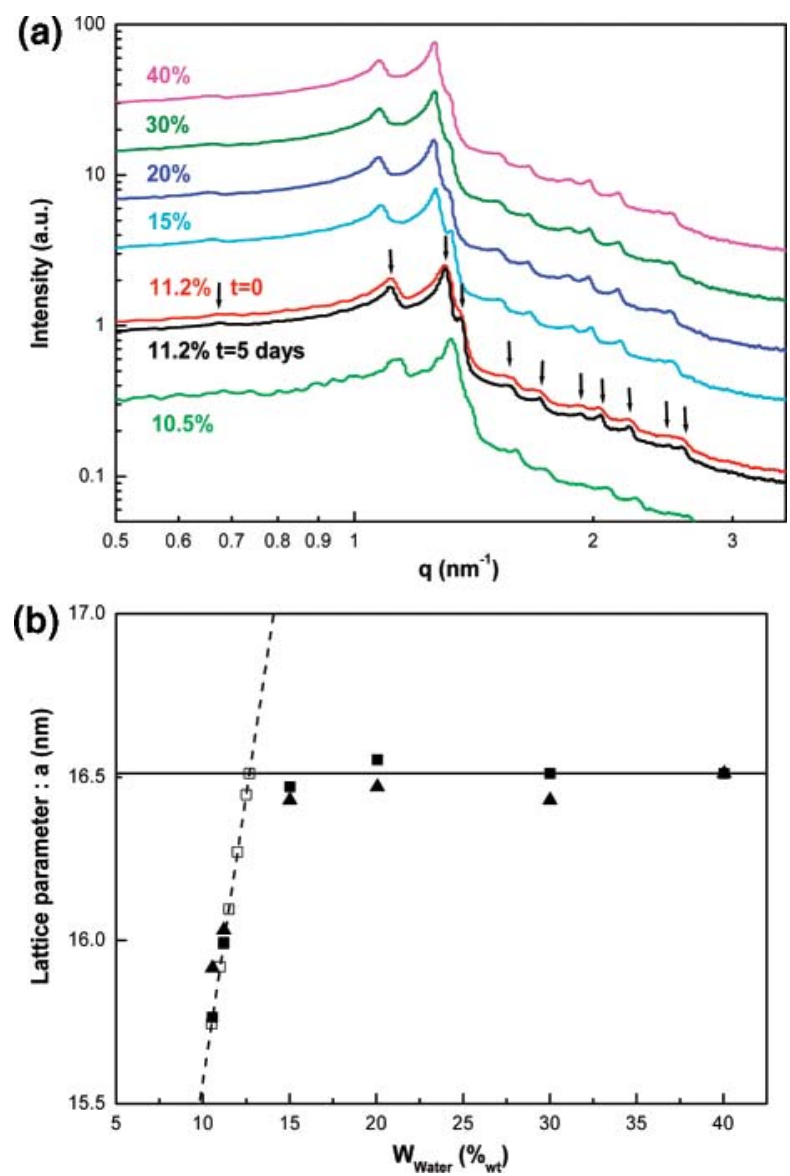

Figure 3. (a) SAXS diffractograms of lipid/water/limonene mixtures with $\alpha=0.4$ at different levels of hydration (from 10.5 to $40 \mathrm{wt}$ $\%$ ) and equilibrated at $23{ }^{\circ} \mathrm{C}$ for 5 days. The amount of water (wt $\%$ ) added to each phase is indicated near the respective SAXS curves. Arrows on the sample of $11.2 \mathrm{wt} \%$ indicate 11 characteristic reflections for the $F d 3 m$ phase corresponding from left to right to the following Miller indices: (111), (220), (311), (222), (400), (331), $(422),(333+511),(440),(620),(551+711)$. (b) Evolution of the lattice parameter $(a)$ with the hydration level $\left(W_{\text {water }}\right)$ of the $F d 3 m$ mesophase for samples with $\alpha=0.4$ just after formation $(t=0$, filled triangles) and after 5 days of equilibration at $23{ }^{\circ} \mathrm{C}$ (filled squares). The samples correspond to those of (a). The solid line corresponds to the mean value of the lattice parameter $(16.51 \mathrm{~nm})$ for samples above full hydration $(12.68 \%)$. The dashed line represents a linear fit for samples below full hydration of the mesophase at $t$ $=5$ days. Open square symbols correspond to values of the lattice parameter interpolated by the linear regression and used for the calculations of Figures 4 and 5.

alkyl tails. These tails would then relax to afford a necessary stretching for the $\mathrm{Fd} 3 \mathrm{~m}$ configuration.

Structural Evolution of the $\mathbf{F d 3 m}$ Phase with Increasing Hydration. The structure of the mesophases built from monolinolein/limonene oil/water ternary systems with increasing amount of water has been determined 5 days after preparation, when full equilibration of the bulk is ensured (see the turbidity curve in Figure 2).

The SAXS curves of Figure 3a show $F d 3 m$ scattering peaks shifted to lower $q$ values when the amount of water is increased (see the diffractograms of samples containing 10.5 and $11.2 \mathrm{wt}$ $\%$ water). This indicates an increase of the lattice parameter of the $F d 3 m$ phase with increasing hydration. We gathered the values of the lattice parameter as a function of the hydration in Figure $3 \mathrm{~b}$. The increase continues up to a value of $12.68 \mathrm{wt} \%$ water, beyond which the lattice parameter of the cubic phase flattens off at a constant value of $16.5 \mathrm{~nm}$. Therefore, the full hydration 
of the $F d 3 m$ phase is deduced at 12.68 wt $\%$ water. Above this value, any water added to the $F d 3 m$ phase cannot be incorporated into the micellar cores, resulting in phase-separated water microdomains. These water domains provide the turbid aspect to the blend at equilibrium (i.e., even after 5 days at $23^{\circ} \mathrm{C}$ ).

The window of the water concentration range where the $F d 3 m$ mesophase is a one-phase sample is very narrow (10.5-12.68 wt $\%$ water). This is consistent with results reported by Yaghmur et al. ${ }^{28}$ in mixtures of monolinolein/tetradecane/water at $\alpha=$ 0.33 in which hydration of $20-25$ wt $\%$ water is necessary to obtain fully hydrated $F d 3 m$ phases. They found a lattice parameter of $22 \mathrm{~nm}$ at full hydration ( $25 \mathrm{wt} \%$ water) of the $F d 3 \mathrm{~m}$ phase, slightly higher than that measured in the blends reported here $(16.51 \mathrm{~nm})$, this resulting apparently from the difference in the oil type used. ${ }^{66}$

Calculation of Topological Parameters Using Models for the Inverse Discrete Micellar Cubic Phase. Two different models ${ }^{42,49}$ have been proposed so far to describe the $F d 3 m$ structure in amphiphile/water/oil ternary systems. They both allow for the calculation of the micelle size $(r)$, the number of amphiphile molecules per micelle $\left(N_{\mathrm{L}}\right)$, and the averaged specific surface area occupied by each amphiphilic molecule at the micelle surface $\left(a_{\mathrm{s}}\right)$. These calculations can be done since the lattice parameter $\left(a_{\text {lattice }}\right)$ and the volume fractions of the polar phase $\left(\phi_{\text {polar }}\right)$ (i.e., water plus hydrophilic heads of the amphiphiles) and the apolar phase $\left(\phi_{\text {apolar }}\right)$ (i.e., oil plus alkyl tails of the amphiphiles) are known. In our case, we calculated these two volume fractions as

$$
\phi_{\text {apolar }}=\phi_{\text {lim }}+\phi_{\text {mono,alkyl tails }}
$$

and

$$
\phi_{\text {polar }}=\phi_{\text {water }}+\phi_{\text {head }}=1-\phi_{\text {apolar }}
$$

The molar mass of the hydrophilic head $\left(M_{\text {head }}\right)$ of a monolinolein molecule was considered to consist of the molar masses of the glycerol moiety and the carbonyl group, leading to $M_{\text {head }}=119 \mathrm{~g} \cdot \mathrm{mol}^{-1}$. The temperature dependences of the density of water, limonene oil, and monolinolein (i.e., Dimodan U) were given in the Materials and Methods.

The overall weight fractions of monolinolein (Dimodan $\mathrm{U}$ ) ( $\left.W_{\text {mono }}\right)$ and limonene $\left(W_{\text {lim }}\right)$ are calculated from $\alpha$ and the weight fraction of water $\left(W_{\text {water }}\right)$ :

$$
\begin{gathered}
W_{\text {lim }}=\alpha\left(1-W_{\text {water }}\right) \\
W_{\text {mono }}=(1-\alpha)\left(1-W_{\text {water }}\right)
\end{gathered}
$$

The model developed by Uddin et al. ${ }^{42}$ for the $F d 3 m$ structure only considers 24 monodisperse micelles, whose core has a radius $r$. We used this model in the water range below full hydration. In this case, all the water is found in the cores of the inverse micelles. Thus, using the values of the lattice parameters deduced from the SAXS measurements (Figure 3b), we calculated the topological parameters of the $F d 3 m$ phase in the monolinolein/ limonene oil/water system at $23{ }^{\circ} \mathrm{C}$ :

$$
r=\left(\frac{3}{4 \pi n_{\text {micelles }}}\right)^{1 / 3}\left[1-\left(\phi_{\text {mono,alkyl tails }}+\phi_{\text {lim }}\right)\right]^{1 / 3} a_{\text {lattice }}
$$

where $n_{\text {micelles }}=24$ is the number of micelles in the unit cell and $a_{\text {lattice }}$ the lattice parameter.

The mean surface area occupied by each monolinolein molecule is evaluated by using the same model as

$$
a_{\mathrm{s}}=\left(\frac{3 \frac{M_{\text {mono }}-M_{\text {head }}}{\rho_{\text {mono }}} \frac{1}{N_{\mathrm{a}}}}{r}\right)\left[\frac{1-\left(\phi_{\text {mono,alkyl tails }}+\phi_{\text {lim }}\right)}{\phi_{\text {mono,alkyl tails }}}\right]
$$

where $N_{\mathrm{a}}$ is the Avogadro number.

The number of amphiphilic molecules per micelle can also be evaluated using the following equation:

$$
N_{\mathrm{L}}=\frac{\phi_{\text {mono,alkyl tails }} a_{\text {lattice }}}{\frac{M_{\text {mono }}-M_{\text {head }}}{\rho_{\text {mono }}} \frac{1}{N_{\mathrm{a}}}} \frac{1}{n_{\text {micelles }}}
$$

Results for $r, N_{\mathrm{L}}$, and $a_{\mathrm{s}}$ obtained using the above equations are displayed in Figure 4. From this model, we can conclude that the $F d 3 m$ structure in this ternary system is made of rather small micelles with a core radius of about $2.25 \mathrm{~nm}$, which approximately comprise 160 monolinolein molecules each occupying a surface of $40 \AA^{2}$.

The main trend shown in Figure 4 is the increase with hydration of both the size of the micelles and the number of lipid molecules forming each micelle, while only a minor change (less than $3 \%$ ) in the average surface area per molecule is calculated. Thus, the increased interfacial area created by the increasing hydration of the micellar cores is stabilized by the adsorption of additional monolinolein molecules, while each of them still occupies the same area $\left(a_{\mathrm{s}}\right)$ at the lipid-water interface.

The second model developed by Minamikawa et al. ${ }^{49}$ is a refinement of the previous one that takes into account the presence of two types of micelles with different sizes as revealed by freeze fracture microscopy and SAXS low-resolution crystallography with reconstruction of the electron density map of the Fd3m mesophase. This model enables calculation of the radii for the smaller and larger types of micelles (i.e., respectively, $r_{\mathrm{p}}$ and $R_{\mathrm{p}}$ ) since $\phi_{\text {polar }}, \phi_{\text {apolar }}$, and $a_{\text {lattice }}$ are known, and considering $a_{\mathrm{s}}$ as a fixed parameter. This last assumption seems to be a reasonable one in ternary systems too (see Figure 4).

According to the model of Minamikawa et al., $r_{\mathrm{p}}$ and $R_{\mathrm{p}}$ are real numbers determined by solving the following equations:

$$
\phi_{\text {polar }} a^{3}=8\left(\frac{4 \pi}{3} R_{\mathrm{p}}^{3}\right)+16\left(\frac{4 \pi}{3} r_{\mathrm{p}}^{3}\right)
$$

and

$$
a_{\mathrm{s}}=\frac{8\left(4 \pi R_{\mathrm{p}}^{2}\right)+16\left(4 \pi r_{\mathrm{p}}^{2}\right)}{n_{\text {micelles }} N_{\mathrm{L}}}
$$

where $R_{\mathrm{p}}>r_{\mathrm{p}}$. The calculation is parameterized with $a_{\mathrm{s}}$.

Using this model, we calculated the radii of both micelles for different levels of hydration at a constant temperature of $23{ }^{\circ} \mathrm{C}$ and for $a_{\mathrm{s}}$ comprised between $a_{\mathrm{s}, \min }=29 \AA^{2}$ and the maximum value corresponding to the value calculated in the previous model given by Uddin et al. ${ }^{42}$ This latter case is a particular case of the model of Minamikawa et al. ${ }^{49}$ when $r_{\mathrm{p}}=R_{\mathrm{p}}=r$.

The minimum value for $a_{\mathrm{s}}\left(a_{\mathrm{s}, \mathrm{min}}\right)$ was evaluated at $29 \AA^{2}$ by considering the cross section of the equivalent cylinder (with the density of Dimodan at $23{ }^{\circ} \mathrm{C}$, i.e., $\rho=1.07 \mathrm{~g} \cdot \mathrm{cm}^{-3}$ ) enveloping the polar head of monolinolein $\left(M_{\text {head }}=119 \mathrm{~g} \cdot \mathrm{mol}\right)$. The length of the cylinder $\left(L_{\text {cyl }}\right)$ was calculated at $6.3 \AA$ by energy minimization of the polar head (Chem 3D), and the area $a_{\mathrm{s}, \min }$ was finally calculated by

$$
\mathrm{a}_{\mathrm{s}, \min }=\frac{M_{\mathrm{head}}}{N_{\mathrm{A}} \rho L_{\mathrm{cyl}}}
$$




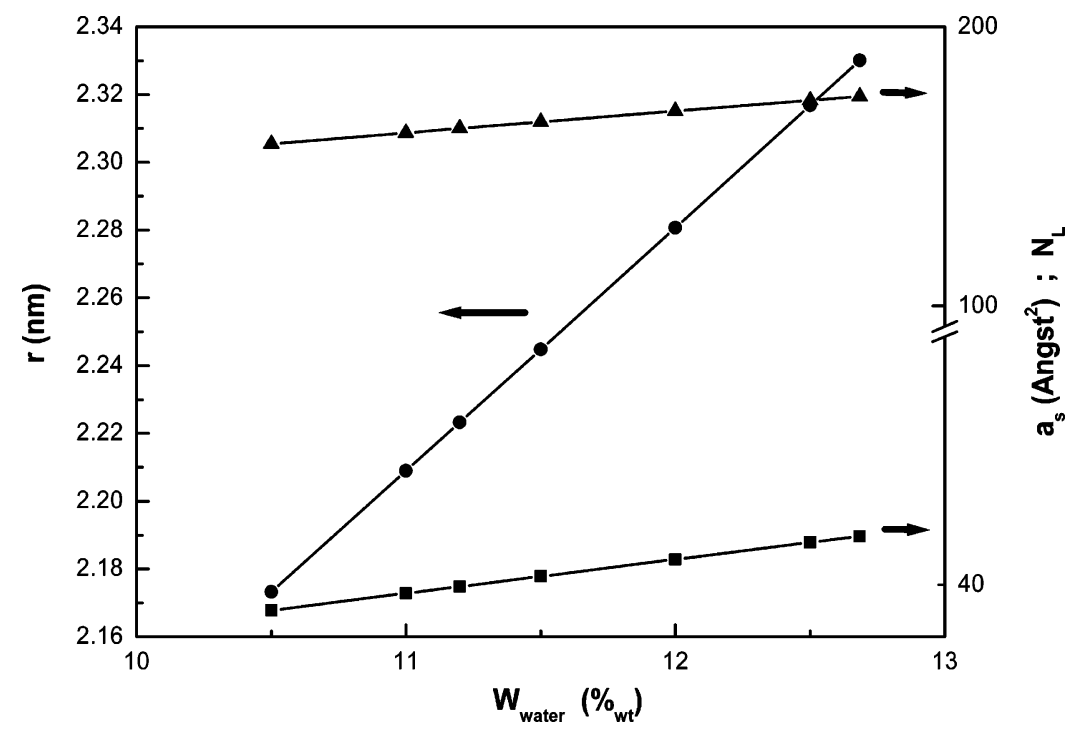

Figure 4. Topological parameters of the $F d 3 m$ structure in bulk samples obtained for $\alpha=0.4$ after 5 days of equilibration at $23{ }^{\circ} \mathrm{C}$ for different amounts of water ranging between 10.5 and $12.68 \mathrm{wt} \%$ (full hydration). Circles identify the radius of monodisperse micelles $(r)$, pentagons give the average surface area per monolinolein surfactant molecule $\left(a_{\mathrm{s}}\right)$, and triangles indicate the number of monolinonein molecules per micelle $\left(N_{\mathrm{L}}\right)$. These values are calculated by eqs $10-12 .{ }^{42}$

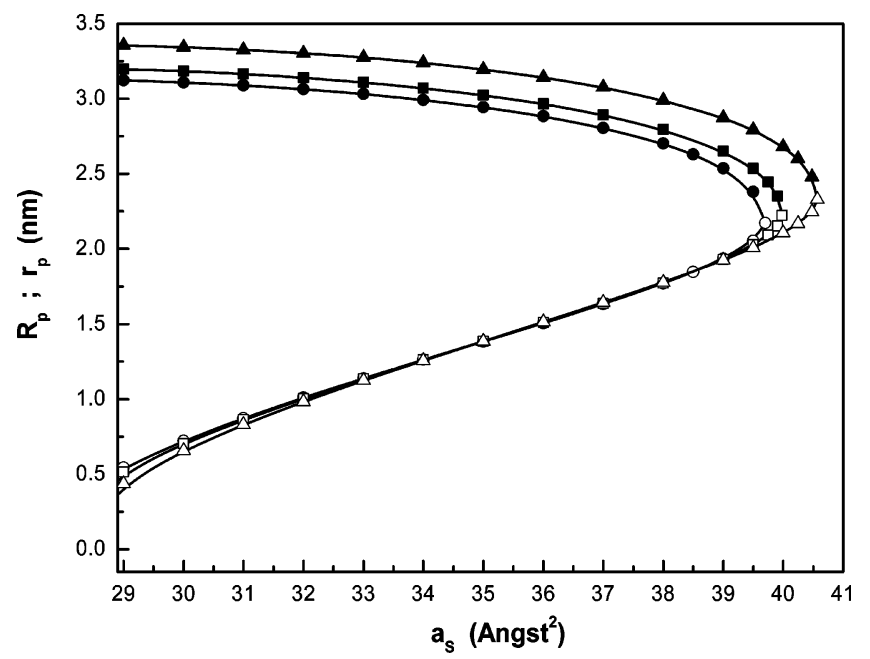

Figure 5. Calculation of the size of smaller $\left(r_{\mathrm{p}}\right.$, open symbols) and larger $\left(R_{\mathrm{p}}\right.$, filled symbols) micelles for an $F d 3 m$ bulk phase obtained for $\alpha=0.4$ after 5 days of equilibration at $23{ }^{\circ} \mathrm{C}$ and for amounts of water of $10.5 \mathrm{wt} \%$ (circles), $11.2 \mathrm{wt} \%$ (squares), and $12.68 \mathrm{wt}$ $\%$ (triangles). The calculations have been made according to eqs 13 and $14 .{ }^{49}$

The results from this second model on three $F d 3 m$ samples at different hydration levels are displayed in Figure 5. They mainly suggest that the size $\left(r_{\mathrm{p}}\right)$ of the 16 smaller micelles does not much depend on the hydration level of the $F d 3 m$ phase, whereas the size of the larger ones $\left(R_{\mathrm{p}}\right)$ increases with the amount of added water. Furthermore, while $R_{\mathrm{p}}$ decreases with $a_{\mathrm{s}}, r_{\mathrm{p}}$ increases. As expected for the sample at the full hydration condition, their difference becomes zero at $a_{\mathrm{s}} \approx 40.6 \AA^{2}$ as predicted by the monodisperse model of Uddin et al. At full hydration the larger size levels off at nearly $3.4 \mathrm{~nm}$, which represents an upper boundary. The corresponding value of $r_{\mathrm{p}}$ is $0.25 \mathrm{~nm}$ and is close to the mean van der Waals value for the diameter of a single water molecule $(\sim 0.32 \mathrm{~nm}) .{ }^{63}$ In summary, depending on the exact value of $a_{\mathrm{s}}$, the radius of the larger micelles is in the range of $2-3 \mathrm{~nm}$, while the smaller ones are between 1 and $2 \mathrm{~nm}$. The maximum possible difference in radius between them is about $2 \mathrm{~nm}$.

\footnotetext{
(63) Finney, J. L. J. Mol. Liq. 2001, 90, 303.
}

Results from both models are in good agreement with previous studies on $F d 3 m$ mesophases obtained from hydrated lipids. In the case of the oleate/oleic acid/water system at full hydration, studied by SAXS, Seddon et al. ${ }^{14,37}$ found micellar radii of $R_{\mathrm{p}}$ $=2.8 \mathrm{~nm}, N_{\mathrm{L}}=226$, and $a_{\mathrm{S}}=43 \AA^{2}$ for the bigger micelles and $r_{\mathrm{p}}=2.2 \mathrm{~nm}, N_{\mathrm{L}}=152$, and $a_{\mathrm{s}}=37 \AA^{2}$ for the smaller micelles, using electron density map analysis. ${ }^{15}$ At full hydration, the present system shows an $F d 3 m$ phase made of micelles with sizes ranging between 1 and $3 \mathrm{~nm}$ and 149-168 monolinolein molecules per micelle depending on the water content (Figure 4).

Rheological Behavior of the $\mathbf{F d 3 m}$ Phase. The frequency dependence of the rheological properties of the $F d 3 m$ micellar cubic phase has been measured under shear at $23{ }^{\circ} \mathrm{C}$ and 11.2 wt $\%$ water for $\alpha=0.4$ just after the blending process $(t=0)$, as well as after 5 and 7 days.

The results are given in Figure 6 and are characteristic of a viscoelastic "hard gel" type LC phase. The large values of the storage modulus on the order of $10^{5} \mathrm{~Pa}$ measured for the $\mathrm{Fd} 3 \mathrm{~m}$ phase are comparable to those previously measured for inverse bicontinuous cubic phases of the Pn3m and Ia3d types. ${ }^{34}$

The addition of an extra hydrophobic component, such as limonene, to monolinolein/water systems enables generation of highly rigid mesophases by structuring them into a micellar cubic phase type at very low levels of hydration. Indeed, the binary monolinolein/water system at the same amount of water and temperature range is stable in a lamellar phase $\left(\mathrm{L}_{\alpha}\right)$ with a critical yield plastic behavior and with a lower storage modulus $\left(\sim 10^{2}\right.$ $\mathrm{Pa})$.

The overall frequency scan observed for the $F d 3 m$ phase at $11.2 \mathrm{wt} \%$ water and $23^{\circ} \mathrm{C}$ is similar to that reported by RodriguezAbreu et al. ${ }^{46}$ for the $\mathrm{Fd} 3 \mathrm{~m}$ phase obtained in blends of PEOPPO-PEO block copolymer/water/xylene oil. They obtained a storage modulus in the range of $5 \times 10^{4} \mathrm{~Pa}$ with the longest relaxation time (corresponding to the inverse of the frequency at which the crossover of the storage and loss moduli is observed) measured at ca. $\tau_{\max }=80 \mathrm{~s}$.

The frequency dependence of the $F d 3 m$ phase reported in Figure 6 is also comparable to the viscoelastic response of the reverse bicontinuous cubic $I a 3 d$ phase of the homologous binary blend. For example, the longest relaxation time $\left(\tau_{\max }\right)$ is of the same order of magnitude as in the $F d 3 m$ phase $\left(\tau_{\max } \propto 10^{2} \mathrm{~s}\right)$ 


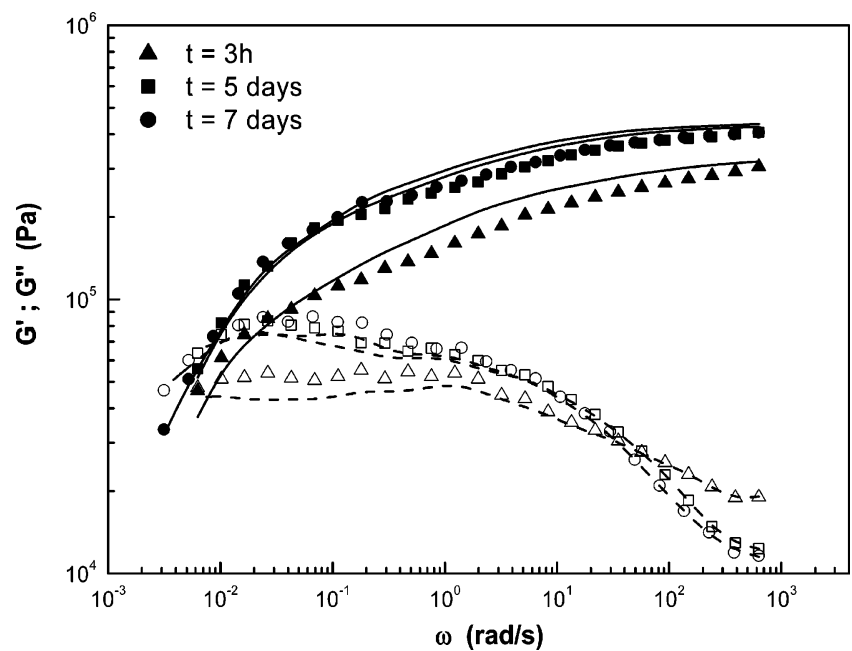

Figure 6. Frequency dependence of the storage modulus $\left(G^{\prime}\right.$, filled symbols) and loss modulus ( $G^{\prime \prime}$, open symbols) measured in the linear viscoelastic regime (strain $10^{-2 \%}$ ) on a bulk $F d 3 m$ mesophase for one sample with $\alpha=0.4$ and $11.2 \mathrm{wt} \%$ water at $23{ }^{\circ} \mathrm{C}$ and after various equilibration times: $t=3 \mathrm{~h}, 5$ days, and 7 days. Solid and dashed lines correspond, respectively, to the best fits for storage and loss moduli at each equilibration time according to a generalized Maxwell model. ${ }^{34}$ The plateau values for the storage modulus at large frequency $\left(G_{0}^{\prime}\right)$ are $G_{0}^{\prime}=3.18 \times 10^{5}, 4.25 \times 10^{5}$, and 4.35 $\times 10^{5} \mathrm{~Pa}$ after $t=0,5$ days, and 7 days, respectively.

when the results corresponding to $I a 3 d$ are extrapolated to the same hydration level used to formulate the $F d 3 m$ phase (i.e., 11.2 wt $\%$ water). ${ }^{34}$

Moreover, we can observe in Figure 6 an overall increase in the storage and loss moduli with time at any specific frequency (compare curves measured at $t=3 \mathrm{~h}$ and $t=5$ days). This is related to the aging of the phase, characterized by a progressive increase with time of the volume fraction of the $F d 3 m$ part in the sample. The increase in rigidity of the blend can be explained, as observed above, by the conversion of the viscous excess water microdomains coexisting with $\mathrm{L}_{2}$ into the viscoelastic $F d 3 m$ domains.

The superimposition of frequency scans for $t=5$ days and $t=7$ days is in accordance with turbidimetry data (Figure 2). It shows that not only optical properties, but also mechanical properties, have been completely attained on the blend after 5 days. This seems to indicate that full equilibrium of the $\mathrm{Fd} 3 \mathrm{~m}$ phase structuration in the bulk occurs within a 5 day lag time.

Using the generalized Maxwell model formalism ${ }^{64}$ and the procedure of Laplace inversion already described elsewhere, ${ }^{34}$ we extracted the time relaxation spectrum $(H(\tau))$ of the $F d 3 m$ phase at $23{ }^{\circ} \mathrm{C}, \alpha=0.4$, and $11.2 \mathrm{wt} \%$ water as shown in Figure 7. The relaxation spectrum can be viewed as the specific mechanical signature of the liquid crystalline mesophase considered.

In Figure 7 , the weights $\left(g_{i}\right)$ indicating the individual contribution to whole complex relaxation for each specific relaxation time $\left(\tau_{i}\right)$ are displayed for the $F d 3 m$ phase (i.e., for $\alpha=0.4)$ and for two types of bicontinuous cubic phases (Pn3m and $I a 3 d$ ) characteristic of the binary mixture monolinolein/ water (i.e., for $\alpha=0$ ). ${ }^{34}$

In the $F d 3 m$ phase a large dominating longest relaxation time can be observed ( $\sim 100 \mathrm{~s}$ ) at complete equilibration (after 7 days). This dominating relaxation time can be attributed to the relaxation of the hydrophilic-hydrophobic interface similarly to the $P n 3 m$ and $I a 3 d$ phases. However, the relaxation spectrum for the $F d 3 m$

(64) Ferry, J. D. Viscoelastic Properties of Polymers; John Wiley \& Sons: New York, 1980

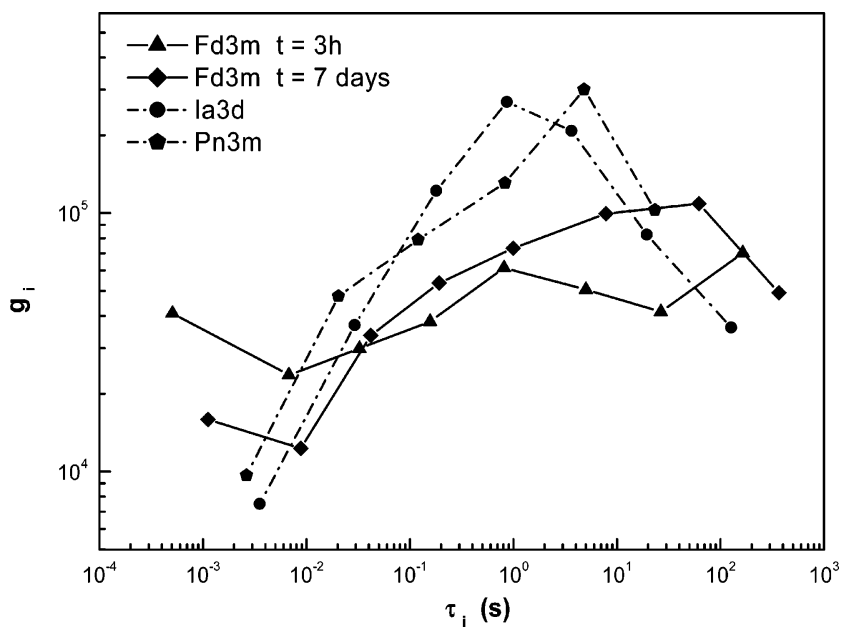

Figure 7. Relaxation spectra $\left(g_{i}, \tau_{i}\right)$ calculated from storage and loss moduli displayed in Figure 6 using the Laplace inversion method for the $F d 3 m$ mesophase of the Dimodan U/water/limonene ternary system with $\alpha=0.4$ and $11.2 \mathrm{wt} \%$ water after $t=3 \mathrm{~h}$ and 7 days at $23{ }^{\circ} \mathrm{C}$. Relaxation spectra previously obtained for bicontinuous cubic phases of the Dimodan U/water binary system $(\alpha=0)$ are also given for comparison: $P n 3 m$ with $20 \mathrm{wt} \%$ water at $55^{\circ} \mathrm{C}$ and $I a 3 d$ with 20 wt $\%$ water at $40{ }^{\circ} \mathrm{C}$.

phase appears much more flat than in the case of the two bicontinuous cubic phases. This equipartition of $g_{i}$ suggests complex relaxation phenomena, involving a cascade of multiple physical events in the relaxation of the $F d 3 m$ phase.

Furthermore, the $F d 3 m$ phase relaxation spectrum and its dominating $\tau$ both appear to be shifted by a decade compared to those of the Pn3m or Ia3d phase. This implies much slower relaxation mechanisms upon application of external shear strain.

The difference in signature of the $F d 3 m$ phase compared to bicontinuous cubic phases may have different physical reasons. First, the shearing of the repeat unit of a bicontinuous cubic phase essentially involves the diffusion of lipids along the infinite periodical minimal surfaces, so that the perturbed equilibrium structure is restored within the relaxation time. In the case of $F d 3 m$, multiple relaxation phenomena may be envisaged to restore equilibrium configuration: (i) diffusion of water from micelles of distinct sizes due to the differential Laplace pressure gradient existing among them, (ii) rearrangement of the deformed interfaces into the dodecahedral and hexakaidecahedral structures, and (iii) packing the perturbed micellar structure back into the $\mathrm{Q}^{227}$ lattice.

Furthermore, the slower kinetics of the relaxation in the $F d 3 m$ phase can also arise from the lower hydration level (11.2 wt \% water) and lower temperature $\left(23{ }^{\circ} \mathrm{C}\right)$ compared to the case of the bicontinuous cubic phases shown in Figure 7, whose relaxation spectra were acquired at $20 \mathrm{wt} \%$ water and 55 and $40{ }^{\circ} \mathrm{C}$ for the $P n 3 m$ and $I a 3 d$ phases, respectively.

In this respect, the previous study on bicontinuous cubic phases $^{34}$ indicated that decreasing water content or temperature leads to an increase of $\tau_{\max }$.

Thermal Behavior of the $\mathbf{F d} \mathbf{3} \boldsymbol{m}$ Phase. The thermal evolution of the structure and rheological properties of the $F d 3 m$ phase formed at $11.2 \mathrm{wt} \%$ water and equilibrated for 5 days at $23{ }^{\circ} \mathrm{C}$ were studied by turbidimetry, optical microscopy, SAXS, and rheology within the temperature range comprised between 17 and $90{ }^{\circ} \mathrm{C}$.

Figure 8 shows the dependence of turbidity from 17 to $31^{\circ} \mathrm{C}$. Between 18 and $28.5^{\circ} \mathrm{C}$ the system is transparent, as shown by the turbidity measured at nearly zero. Below $18^{\circ} \mathrm{C}$ and above 


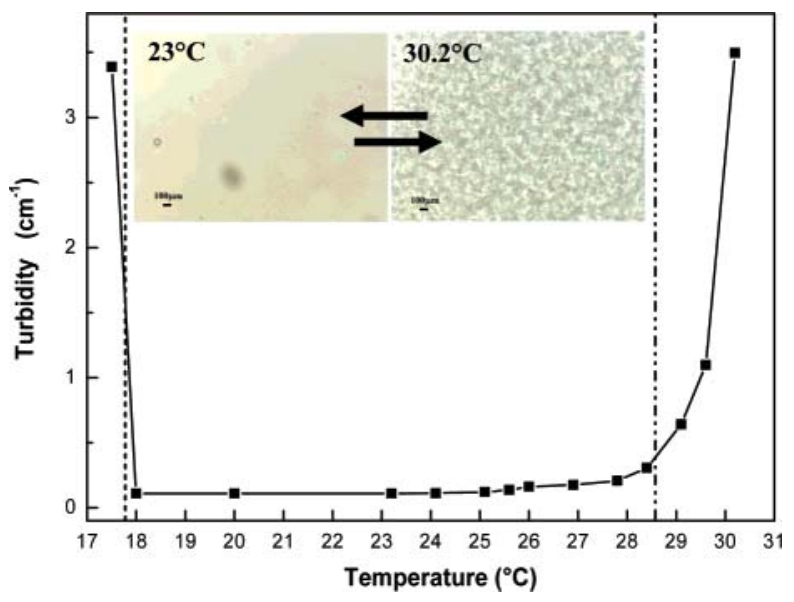

Figure 8. Temperature dependence of the turbidity measured at $\lambda$ $=500 \mathrm{~nm}$ for an $F d 3 \mathrm{~m}$ mesophase bulk sample for $\alpha=0.4$ and 11.2 wt $\%$ water after 5 days of equilibration at $23^{\circ} \mathrm{C}$. Inset: microscopy pictures of the sample at 23 and $30.2{ }^{\circ} \mathrm{C}$. Turbid microdomains observed at $30.2{ }^{\circ} \mathrm{C}$ are related to the presence of the $\mathrm{L}_{2}$ phase, which coexists with phase-separated water embodied in an $F d 3 m$ transparent continuous matrix. The dotted line $\left(18{ }^{\circ} \mathrm{C}\right)$ gives the onset for the Dimodan $\mathrm{U}$ crystallization, and the dashed line $\left(28.5^{\circ} \mathrm{C}\right)$ corresponds to the onset of phase transition between the $F d 3 m$ phase and the $\mathrm{L}_{2}$ phase plus water.

$28.5^{\circ} \mathrm{C}$, we observe a sharp increase in the turbidity, reflecting structural changes in the sample (Figure 8).

Below $18^{\circ} \mathrm{C}$, the observation of the turbid sample under crosspolarized light reveals birefringent domains, which may be associated with crystallization of the monolinolein.

Above $28.5^{\circ} \mathrm{C}$, the examination of the sample by optical microscopy reveals the presence of small microdomains embodied in a transparent continuous phase made of $F d 3 m$ mesophase (see the insets in Figure 8). This evolution of the turbidity upon heating indicates that the transparent continuous phase progressively transforms into a turbid one.

The investigation of the structure by SAXS suggests that the turbid blend is made of a coexistence of $F d 3 m$ domains and an isotropic $\mathrm{L}_{2}$ fluid. Indeed, that isotropic fluid was revealed by SAXS diffractograms at higher temperatures (Figure 9). However, the $\mathrm{L}_{2}$ phase is likely to be associated with an excess of water, as demonstrated by (i) the turbidity of the domains and (ii) the macroscopic phase separation observed at $90{ }^{\circ} \mathrm{C}$. Indeed, while between 28.5 and $40{ }^{\circ} \mathrm{C}$ the SAXS signature indicates that the blend is still mostly formed by $F d 3 m$ domains, this system is completely melted to an isotropic fluid at $40-45^{\circ} \mathrm{C}$. This was evidenced by the disappearance of the reflections of the $F d 3 m$ phase to yield a single broad peak with a maximum ranging between 1.33 and $1.43 \mathrm{~nm}^{-1}$. Such a broad peak is typically from a disordered micellar fluid with a characteristic length scale between 4.4 and $4.7 \mathrm{~nm}$. This was observed up to $90{ }^{\circ} \mathrm{C}$; nevertheless, the opacity of the system indicates the presence of coexisting water.

Such direct thermal transition from an $\mathrm{Fd} 3 \mathrm{~m}$ to an $\mathrm{L}_{2}$ phase has already been shown for a blend of phosphatidylcholine/fatty alcohol/water at higher temperatures. ${ }^{48}$

The temperature range necessary to obtain a stable $F d 3 m$ phase in the present system $\left(18-45^{\circ} \mathrm{C}\right)$ is similar to that reported for a hydrated phosphatidylcholine/diacylglycerol mixture $\left(25-40{ }^{\circ} \mathrm{C}\right) .{ }^{35}$

We have followed the evolution of the lattice parameter $\left(a_{\text {lattice }}\right)$ and characteristic length $\left(d_{\mathrm{L}_{2}}\right)$ under temperature changes (Figure 10). We show that they progressively decrease with increasing temperature. This is a typical behavior found in water-based LC

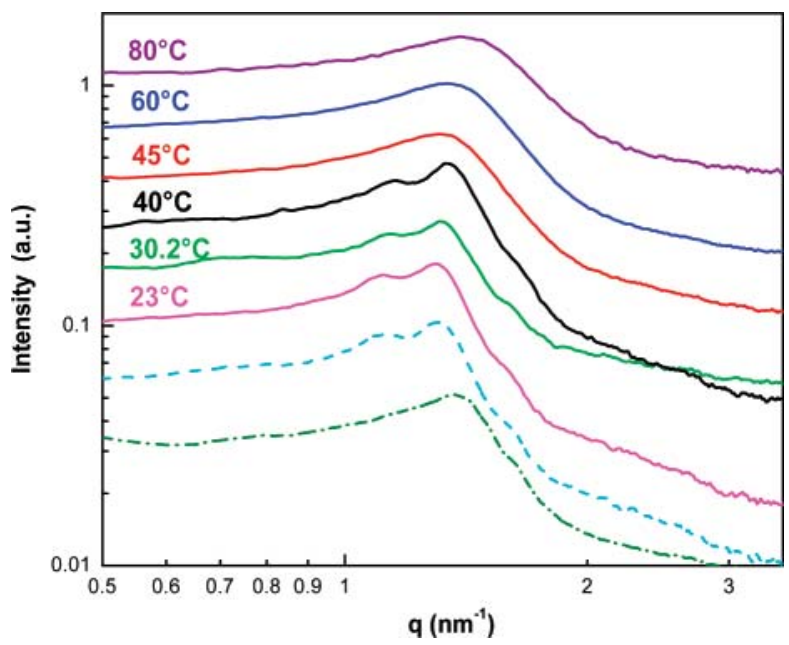

Figure 9. Temperature dependence of the $F d 3 m$ structure for $\alpha=$ 0.4 and $11.2 \mathrm{wt} \%$ water measured by SAXS after equilibration for 5 days at $23{ }^{\circ} \mathrm{C}$. The different curves correspond to temperatures (from bottom to top solid lines) of $23,30.2,40,45,60$, and $80{ }^{\circ} \mathrm{C}$. These results show a transition from a characteristic diffractogram of an $\mathrm{Fd} 3 \mathrm{~m}$ phase below $40^{\circ} \mathrm{C}$ to a characteristic diffractogram of an $\mathrm{L}_{2}$ phase above $45^{\circ} \mathrm{C}$. The dashed lines correspond to cooling at $23{ }^{\circ} \mathrm{C}$ after previous heating at $30.2{ }^{\circ} \mathrm{C}$ (cyan) or $90{ }^{\circ} \mathrm{C}$ (olive).

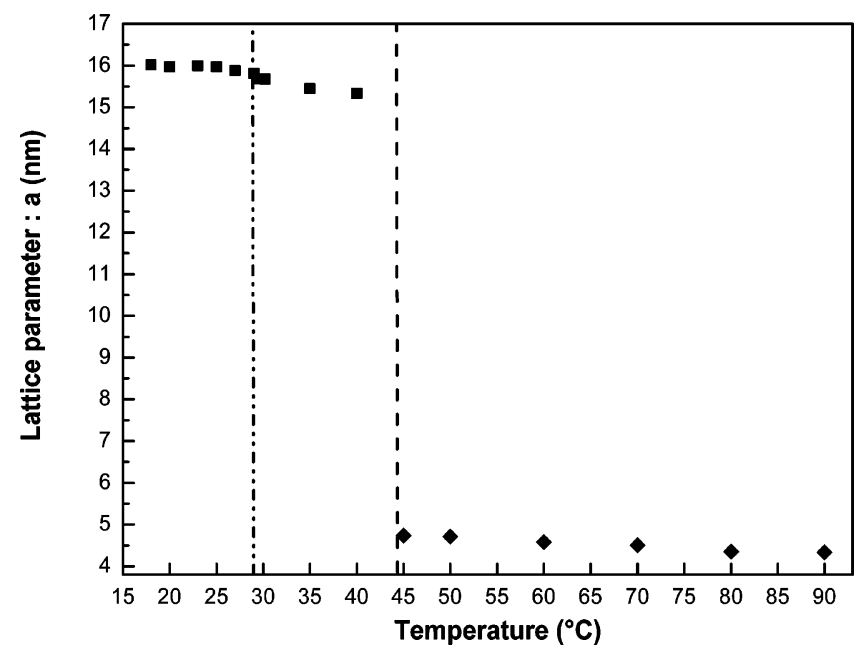

Figure 10. Evolution of the lattice parameter $\left(a_{\text {lattice }}\right)$ and characteristic length $\left(d_{\mathrm{L}_{2}}\right)$ with temperature as measured by SAXS for the $\mathrm{Fd} 3 \mathrm{~m}$ mesophase displayed in Figure 9. Square symbols between 15 and $29^{\circ} \mathrm{C}$ correspond to the lattice parameter of the $F d 3 m$ bulk, square symbols between 29 and $45{ }^{\circ} \mathrm{C}$ correspond to the lattice parameter of the $F d 3 m$ phase coexisting with $\mathrm{L}_{2}$ and water, and tilted square symbols correspond to the characteristic length $\left(d_{\mathrm{L}_{2}}\right)$ of $\mathrm{L}_{2}$ coexisting with water.

phases $^{26,28,33,34,65}$ where the hydrophilic lipid head is monotonously dehydrated with temperature. In Figure 10, we also enhance discontinuities related to the different temperature ranges corresponding to the $F d 3 m, F d 3 m+\mathrm{L}_{2}+$ water, and $\mathrm{L}_{2}+$ water phases.

A similar slight decrease of the lattice parameter with increasing temperature has already been shown for the $F d 3 m$ mesophase made of a hydrated phosphatidylcholine/fatty alcohol blend. ${ }^{48}$

(65) Geil, B.; Feiweier, T.; Pospiech, E. M.; Eisenblatter, J.; Fujura, F.; Winter, R. Chem. Phys. Lipids 2000, 106, 115.

(66) Guillot, S.; Moitzi, C.; Salentinig, S.; Sagalowicz, L.; Leser, M. E.; Glatter, O. Colloids Surf., A: Physiochem. Eng. Aspects 2006, 291, 78.

(67) Charvolin, J.; Sadoc, J. F. J. Phys. 1988, 49, 521 


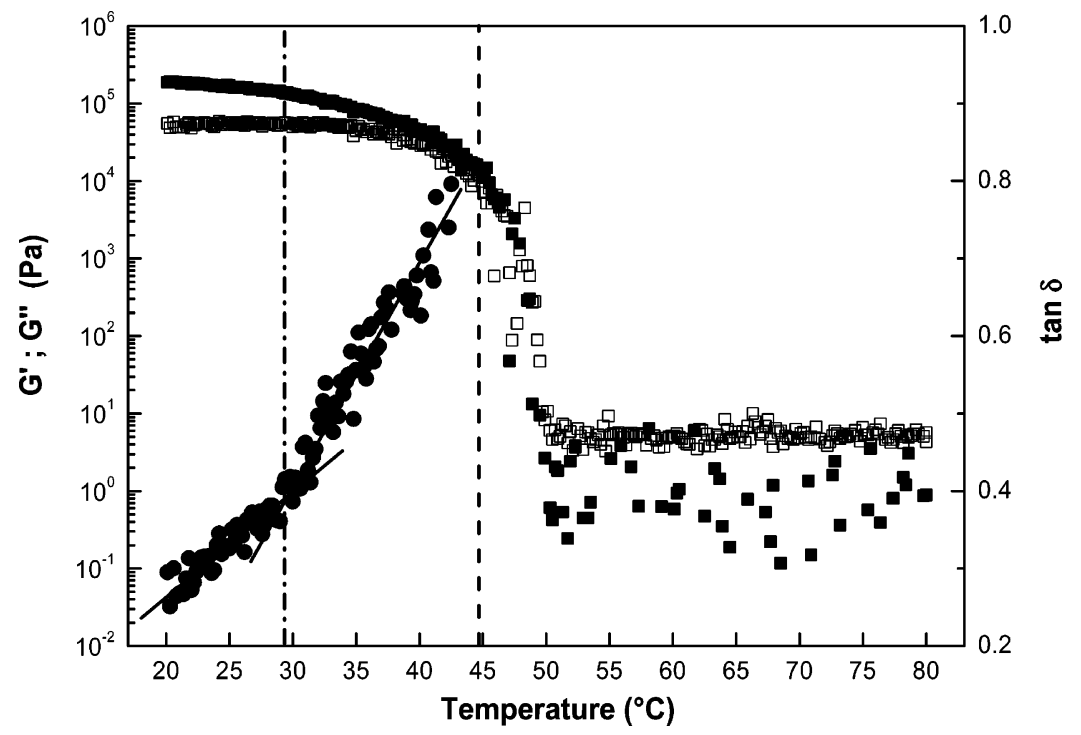

Figure 11. Temperature evolution of the storage modulus $\left(G^{\prime}\right.$, filled squares), loss modulus ( $G^{\prime \prime}$, open squares) and tan $(\delta)$ (filled circles) measured for an $F d 3 m$ phase for $\alpha=0.4$ and $11.2 \mathrm{wt} \%$ water after 5 days of equilibration at $23{ }^{\circ} \mathrm{C}$. The heating rate was $0.2{ }^{\circ} \mathrm{C} / \mathrm{min}$. The solid lines given for $\tan (\delta)$ are guides to the eyes and denote a change in the slope at ca. $29.5^{\circ} \mathrm{C}$. Dotted and dashed lines give phase transitions from $F d 3 m$ to $F d 3 m+\mathrm{L}_{2}+$ water and from $F d 3 m+\mathrm{L}_{2}+$ water to $\mathrm{L}_{2}+$ water.

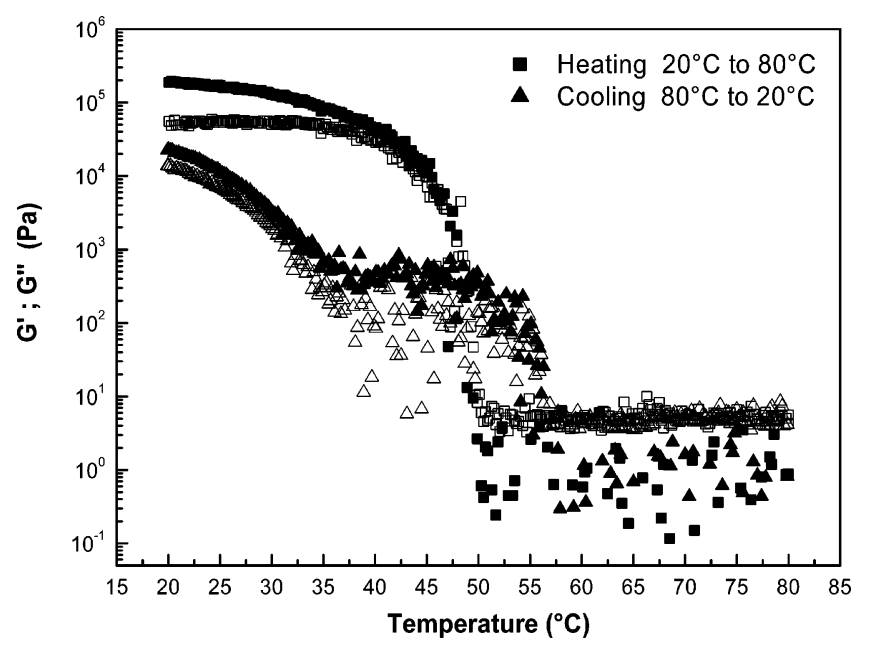

Figure 12. Temperature evolution upon heating and cooling of the storage modulus $\left(G^{\prime}\right.$, filled symbols) and loss modulus $\left(G^{\prime \prime}\right.$, open symbols) for an $F d 3 m$ mesophase with $\alpha=0.4$ and 11.2 wt $\%$ water after 5 days of equilibration at $23{ }^{\circ} \mathrm{C}$. A rate of $0.2{ }^{\circ} \mathrm{C} \cdot \mathrm{min}^{-1}$ has been used for both cooling and heating. The discrepancy in the rheological measurements for $G^{\prime}$ and $G^{\prime \prime}$ between heating and successive cooling are the result of macroscopic phase separation occurring at high temperatures $\left(80^{\circ} \mathrm{C}\right)$.

We have studied changes in rheological behaviors upon heating of the $F d 3 m$ inverse discrete micellar cubic phase $(\alpha=0.4$ and 11.2 wt $\%$ water). The evolution of $G^{\prime}, G^{\prime \prime}$, and $\tan (\delta)$ with a slow heating from 20 to $80^{\circ} \mathrm{C}$ is displayed in Figure 11 . Changes are consistent with previous SAXS measurements and microscopy observations on the structural evolution with temperature. Two major phase transitions can clearly be observed from the rheological measurements. The first one corresponds to the onset of the melting of the highly rigid $F d 3 m$ phase to yield a coexistence region of $\mathrm{L}_{2}+$ water $+F d 3 m$. This transition is clearly indicated by an increase in the slope of $\tan (\delta)$ at ca. $29^{\circ} \mathrm{C}$. The second one is illustrated by the sharp drop in $G^{\prime}$ and $G^{\prime \prime}$ observed between 40 and $45^{\circ} \mathrm{C}$. This drop may be explained by the complete loss of the rigidity associated with the viscoelastic $F d 3 m$ phase to yield a viscous $\mathrm{L}_{2}+$ water mixture.
The reversibility of these transitions has been investigated by SAXS and rheological measurements. As expected, it appears that the transition at $28.5^{\circ} \mathrm{C}$, which consists in the onset of $F d 3 m$ $+\mathrm{L}_{2}+$ water coexistence, is fully reversible. This is shown by the superimposition of SAXS curves (see Figure 9) of samples at $23{ }^{\circ} \mathrm{C}$ and samples submitted to a thermal history of $20{ }^{\circ} \mathrm{C}$ $\rightarrow 30{ }^{\circ} \mathrm{C} \rightarrow 20^{\circ} \mathrm{C}$ (after 5 days of equilibration for each sample). Analogously, the transparency of the blend is fully recovered upon cooling to $23{ }^{\circ} \mathrm{C}$ within $2 \mathrm{~h}$.

Nevertheless, concerning the second transition characterized by the complete melting of the $F d 3 m$ phase above $45^{\circ} \mathrm{C}$, the $F d 3 m$ phase could not be recovered when the mixture was cooled from $45{ }^{\circ} \mathrm{C}$ back to $23{ }^{\circ} \mathrm{C}$. Indeed, the sample still exhibits the signature of an $\mathrm{L}_{2}$ phase at $23{ }^{\circ} \mathrm{C}$ (see Figure 9). However, this sample showed evidence of macroscopic phase separation.

We have measured the rheological parameters on an $F d 3 m$ sample subjected to two successive temperature sweeps from 20 to $80^{\circ} \mathrm{C}$ and subsequent reverse cooling from 80 to $20^{\circ} \mathrm{C}$ (Figure 12). The rheological results are consistent with the previous observations, as mismatch of $G^{\prime}$ and $G^{\prime \prime}$ acquired on a sample equilibrated 5 days at $23{ }^{\circ} \mathrm{C}$ and those having followed the $20{ }^{\circ} \mathrm{C} \rightarrow 80{ }^{\circ} \mathrm{C} \rightarrow 20^{\circ} \mathrm{C}$ cycle is obvious. These observations do not state that the transition at $45^{\circ} \mathrm{C}$ is irreversible, but rather that a macroscopic phase separation prevents the system from recovering the thermodynamically stable configuration, unless external mixing is carried out.

\section{Conclusions}

The present study shows that the addition of a hydrophobic component, such as the food-grade limonene, to the monolinolein/ water binary system in a well-defined composition $(\alpha=0.4)$ allows stabilization of a rigid inverse discrete micellar $F d 3 m$ cubic phase in the bulk. This phase does not exist in the homologous binary mixture, where comparable LC phases in terms of viscoelastic properties are bicontinuous phases such as $P n 3 m$ and $I a 3 d$.

The $F d 3 m$ phase has a very slow kinetics of formation, as a consequence of partitioning of water into two populations of micelles with different sizes. The $F d 3 m$ phase formed at $\alpha=0.4$ is stable in the bulk up to a maximum hydration of $12.68 \mathrm{wt} \%$. Beyond that limit, a coexistence with excess water occurs. At 
full hydration the $F d 3 m$ phase is made of 16 smaller micelles and 8 larger micelles per cubic lattice cell, having sizes ranging between 1 and $3 \mathrm{~nm}$ and 149-168 monolinolein molecules per micelle depending on the water content.

The temperature dependence of the structural and rheological properties of the $\mathrm{Fd} 3 \mathrm{~m}$ mesophase has been investigated using SAXS, rheology, and turbidimetry. As evidenced by SAXS and rheology, the hydrophobic domains of the $F d 3 m$ phase undergo crystallization below $18^{\circ} \mathrm{C}$, while above $28.5^{\circ} \mathrm{C}$ the $F d 3 m$ phase begins to melt into a mixture consisting of an inverse microemulsion $\left(\mathrm{L}_{2}\right)$ and water. Complete melting of the $F d 3 m$ phase is achieved at $40-45^{\circ} \mathrm{C}$. Macroscopic phase separation between the $\mathrm{L}_{2}$ phase and excess water is observed with time at higher temperature.

The investigation of the viscoelastic properties of the $F d 3 m$ inverse discrete micellar cubic phase allowed establishment of a dominant relaxation time and a rheological signature similar to that observed in bicontinuous cubic phases $(P n 3 m$ and $I a 3 d)$ of homologous binary systems.

Yet the $F d 3 m$ phase exhibits a complex set of slower relaxation mechanisms, which lead to a shift by 1 order of magnitude of the dominant relaxation time and whole relaxation spectrum found in reverse bicontinuous cubic phases. These findings have been tentatively explained by the multiple relaxation mechanisms that micelles undergo upon shear deformation, by the small hydration level of the $F d 3 m$ phase, and by the low temperature at which the $F d 3 m$ phase can be observed in bulk.

Acknowledgment. We thank Alejandro Marabi for useful discussions, Nadia Canilho for technical assistance in the SAXS measurements, and Nestlé management for allowing publication of the present work. 